\title{
Non-Target Nodal Lesion Identification
}

National Cancer Institute

\section{Source}

National Cancer Institute. Non-Target Nodal Lesion Identification. NCI Thesaurus. Code C132470.

The identification of a tumor or lesion located at or near the lymph node that is present at baseline, and is not the target of the therapeutic intervention. 